\title{
Challenges and New Directions in Control Engineering Education
}

\author{
Kai Zenger \\ Department of Electrical Engineering and Automation, Aalto University, Finland, Kai. Zenger@aalto.fi
}

\begin{abstract}
The paper discusses the changes and challenges in the current teaching of Automatic Control systems. Modern society has developed into a phase where the traditional process industry is not at all the only area where dynamic modelling, understanding the feedback, control engineering, autonomous systems and generally the discipline of Automatic control have to be mastered. That gives a huge challenge to the teaching of automatic control in general, especially when fewer and fewer students are entering engineering schools and as the basic skills in mathematics and physics seem to be decreasing everywhere. On the other hand, automation (to be understood broadly including automatic control and control engineering, autonomous systems etc.) as a discipline is in a state of change: it seems to be hidden in other engineering fields, and there seems to be opinions that it should actually be taught within specific application areas, e.g. in electrical engineering, machine design, chemical process engineering etc. In the old school of control engineering the idea is actually vice versa: automatic control is seen as a general, mathematically and physically well-defined discipline, which can the be applied in various application areas and engineering fields. The societal and industrial viewpoints must both be considered, when looking at the future of control education. These aspects are discussed in the paper.
\end{abstract}

Keywords: education, automatic control, autonomous systems, control engineering, curriculum

\section{Introduction}

Control engineering, control theory or system theory are the cornerstones of automatic control or autonomous systems in general. The interdisciplinary nature of control and applications is shown as an example case in Figure 1, where the classical idea of control theory serving a multitude of application areas is demonstrated, (Zenger, 2007).

The above age old idea has been good and well-serving for a long period of time, but today in the modern society there are aspects that suggest a change. Firstly, control has always been considered a difficult topic for the students to learn, and this attitude is getting stronger as the mathematical skills of students are generally considered weaker than before (Rasila et al., 2007). Secondly, the status of automation is perceived weaker, as there is a trend to consider it a part of other well-established engineering fields only, and not a research field of its own right. In

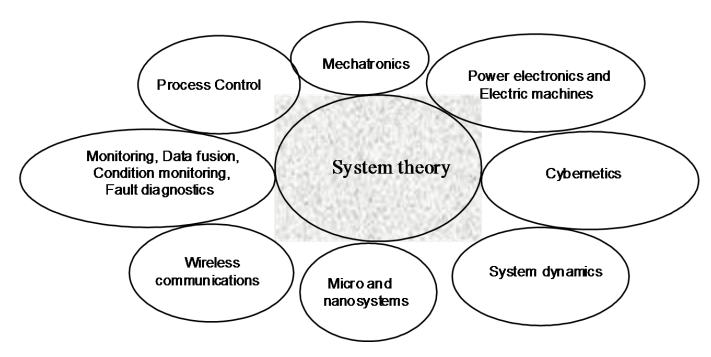

Figure 1. Application fields of control engineering.

addition, the application of dynamic modelling, optimization and feedback control for example, has been extended to a much broader field than before. Cyberphysical systems, Information theoretical systems including communication and the Internet, Big Data, Cloud Computing, Internet of Things produce totally new applications, which need control theory and signal processing. In this respect, the ideas and "new" curriculum for control education (see e.g. (Kheir et al., 1996; Murray, 2003)) are already somewhat out of date.

The relevant contemporary questions from the education viewpoint are:

- Is automation losing its position as an independent research field and is it going to be combined with other research disciplines?

- The elegant combination of signal processing, control, mechanics etc. is actually hidden in products. Is the value of control not seen anymore?

- The level of teaching automatic control has in general been of high quality. In the industry the graduated students have obtained good positions. How is the situation now and in the future? How can these kinds of issues be "controlled"?

- Should the universities and universities of applied sciences specialize in teaching only some application areas of automation or keep the wide view?

- How is the financing of teaching automation going to develop in the near future?

- What must a graduating student from the automation field know and master now and in the future? 
- What about the connections and networking by teachers, students and industrial representatives on a regular basis.

In the paper it is not possible to discuss and solve all the above questions. However, it is important to pose these problems for general awareness and for discussion. That is one target of the paper.

The contents of the paper can briefly be stated as follows. The pedagogical issues, teachers' challenges and comparison to teaching of mathematics are discussed in Section 2. What practical changes and new ideas in control engineering education would be useful to introduce in the modern curriculum in universities and universities of applied sciences is discussed in Section 3. A look into the future is shown in Section 4 and Conclusions are given in Section 5.

\section{Control Engineering: The Teacher's Challenge}

Control engineering is considered to be a difficult topic to teach. The formalism (given originally by system theory) is based on a firm understanding of basic sciences like mathematics and physics. The background and basic skills in natural sciences of the students vary a lot. It seems that there is a tendency that basic mathematics skills of the students has decreased (Rasila et al., 2007). There are a lot of reports indicating this, but maybe equally valuable is the "touch" of university teachers. According to their opinion the general level of the students in mathematics has decreased considerably in over the past $10-20$ years. In engineering schools the attitude of the students in respect to this is usually something like "I have come here to study engineering, not mathematics". Indeed, that is somewhat of a strong argument. Today it seems difficult to persuade the students to accept mathematical rigor by sayting that "the laws of nature have been written in the language of mathematics" or something alike. The youth of today have so much other interests and things to do that they do not want to spend their time in learning mathematics.

A natural extension to the above is to state that teaching control engineering generally as a self-contained theory to serve different applications areas later may not be well understood by the students. Teaching control theory this way is seen as some kind of a new course of mathematics again. Questions and comments like "Why teach everything to everybody?", "Why teach theoretical issues that an engineer does not need in his/her daily work? and "You see - some people do not need these things - ever!" have been asked by the students in numerous occasions where the courses have been evaluated (Zenger, 2007). These questions and the related pedagogical challenge can be analysed using e.g. Ausubel's taxonomy (Ausubel, 1968), which makes a distinction between mechanical, meaningful, assimilative and inventive learning.

It seems logical to assume that this taxonomy is still valid in analyzing the learning process in general. The modern society demands meaningful and inventive learning methods to be used, in order to speed up the studies and get the students to graduate as fast as possible. The old-fashioned teaching methods might be assimilated to more mechanical learning style, which, under the new hypothesis might not be so effective. However, the different students with totally different learning styles are not really consided by this kind of thinking. It is the experience of the author, based on several decades of experience in teaching control systems, that good students learn in spite of teaching, bad students do not learn because they are not motivated, the other students can really be helped by innovative and good teaching practises.

There has been some discussion and doubts about the effectiveness of traditional lectures. The general trend in university level pedagogy researchers seems to be that lectures are not a good teaching method, because they only call for passive learning. It must be admitted that student activation really seems to be (also in Ausubel's taxonomy) the critical point here. Learning by doing seems an effective learning method, if carried out in a good way. But it is not a trivial thing to see, how teaching in this way should really be carried out. If it is done in every course it gives a high work load to the students, who very fast turn critical towards it. Also, there are students who simply like the lectures / exercise hours mechanism. The concept of Problem-based learning (Boud and Feletti, 1977) has not been widely used in engineering schools. Surely, applications using the ideas of PBL have been developed and used on laboratory exercises and web courses, see e.g. (Riihimäki et al., 2003; Pohjola et al., 2005).

However, it must always be borne in mind that lectures for a large audience (say, 100-300 students) are really a cheap way to teach. The financiation of teaching is nowadays a very difficult issue.

Comparison of the teaching of control and mathematics is indeed fruitful, because they seem to somehow share similar problems. In basic university level mathematics courses the web-based interactive study material has been tried with success. For example the STACK system has been used (Rasila et al., 2007) to make varying drill problems to the students, who can solve them when and whereever they are, and the results evaluation is really used partly in grading the course. A similar course material was also used in Control education in Helsinki University of Technology (now Aalto University), although in a much smaller scale. It can be concluded that for drill problems the system is effective, but not for real design problems of engineering. On the other hand, computerbased examinations have been discussed a lot lately. The conclusion has so far been that for examinations where only essay kind of answers or very simple drill problems are required, the existing solutions are usable. However, for examinations of more advanced courses with problem solving the existing software is not good enough. For the time being there is a good reason to seek alternative solutions in order to develop teaching. 


\section{New Curriculum For Teaching Au- tomatic Control}

Based on the above there is a good reason to develop new ideas and methods to be used in teaching automation. In the modern era the application areas range from traditional process control to control of electric drives, applications in power electronics and electrical networks, smart grids, mobile networks and systems, digital systems, robotics, sensor networks, social networks etc. Especially communication in all levels is much more important than it used to be in traditional control engineering. The connection between signal processing and control engineering becomes even more important as it has usually been regarded. Similarly, information technology in general is very relevant in modern control applications. Consequently, there have been ideas to combine the two fields. For example, in Aalto University it is possible to apply to the bachelor level program Automation and Information technology. The studies are similar during the first year, after which the students will choose, whether they want to concentrate on information systems or automation.

In order to study, what has to be taught let us see the bachelor level curriculum (basic studies).

- Mathematics (25 cr.)

- Physics (10 cr.)

- Python-programming (5 cr.)

- C-programming (5 cr.)

- Hands-on course (8 cr.)

- Signals and systems (5 cr.)

- Mathematics software (2 cr.)

- Languages (5 cr.)

- Other (5 cr.)

The curriculum is more or less traditional with a few noticeable points. The amount of mathematics is considerable less than it used to be. Programming skills are considered important. Also, the Hands-on course is mandatory to all 1 st year students. In that course the students work in groups with small introductory projects. For example, Arduino equipment and small robots are used to construct small devices. Electrical measurements and design, mechanical construction and design, programming and control are used in relatively simple settings. The idea is that the students get interested to appreciate the need to learn later more on the theoretical aspects, after first having done practical examples. (There remains a lot of unclear issues in the examples, e.g. in programming, signal processing and control, which should wake the students' interest to study more).

Still in bachelor level studies the major in automation and information technology looks like this.
- Bachelor seminar and thesis (10 cr.)

- Introduction to information technology (5 cr.)

- Introduction to Automation and systems technology (5 cr.)

- Automation 1 (5 cr.)

- Automation 2 (5 cr.)

- Laboratory course in automation (5 cr.)

- Control Engineering (5 cr.)

- Robotics (5 cr.)

- Basics of chemistry (5 cr.)

- Machine design (5 cr.)

- Electrical engineering and electronics (5 cr.)

Here the main issue to note is that both information technology and automation and systems technology are mandatory courses. After completing them the students will choose, which major of the two they will take.

The curriculum gets even more interesting in the major level. All teaching there is in English. In the Automation major the following seven courses are mandatory

- Embedded real-time systems (5 cr.)

- Product development (5 cr.)

- Project work course (10 cr.)

- Distributed and intelligent automation systems (5 cr.)

- Dynamical systems and identification (5 cr.)

- Stochastics and estimation (5 cr.)

- Advanced control (5 cr.)

In addition to this a broad selection of optional courses is available in a course bank from which the students can choose whatever courses they please to complete the major. There are certain paths which are suggested to take for certain specialization, but these are only suggestions. Like stated, the student is free to choose the courses.

The amount of product development oriented courses has been increased in the current program, and that is a clear plan in bringing the new teaching methods into play. Embedded real-time systems, product development and project work courses demonstrate this. Especially interesting is the project work course, which is a one-year-long course, where the students work in groups to carry out a projects given by research groups of the school. The problems are such that they are related to real research work, whenever this is possible (and usually it is). The instructors come from the research groups, and several sessions 
and schooling to the instructors are given. The course includes lectures where project management, project planning, IPR rigts, group dynamics, business plan planning etc. are considered. The students choose a project manager from their group and there are project meetings on regular intervals (usually once in one or two weeks). Both agendas and minutes are written by the group members and that and other relevant material is managed in a suitable electronic project management system. In addition to that the course arranges mid-term presentations to the whole course where poster walks are arranged and each project is presented. A final gala is arranged in the end of the course. There the results are presented, including comments on how the project work felt and succeeded.

Peer evaluation is used as a part of determining the grade for each student. Here the students evaluate not only themselves but each other also. It is then the instructor who puts all information together and proposes the grades to the students. Usually that is the final grade, even though the responsible teacher of the course can intervene (usually not).

Although the project work course seems at a first glance a bit formal, it is actually a very good modern course. The students can use their imagination and talent to do new things, in a way that is supported by the methods and procedures of the work in start-ups and other companies. Some parts come near to the concept on peer instruction (Mazur, 1997), but as a whole the course goes even further in modern ideas of innovative, practical, yet theoretically challenging, engineering work.

In short, the new ideas implemented in the university level study curriculum in automation and control can be summarized as follows. A hands-on course is arranged already in the beginning of studies to give some practical work to the students and to wake their interest, motivation and need to study also theoretical courses. In theoretical courses more exercises and design problems are given, to be done alone or in a group in a time that is best suitable to the student(s). The amound of lectures is decreased and more weight in evaluation is given to the homeworks and design problems. Examination still exists, but it is more like a check that everybody in the courses masters the key material. In the examination there is not enough time to solve but rather simple exercises. It is much better to give time to the students, to work individually or in groups when they please. Usually, there is about two weeks time to solve one design problem.

The relatively large project work course was already explained above. It is a cornerstone in the new study program. It is not arranged only to the students of automatic control, but also to other students in different disciplines in the School of Electrical Engineering.

In addition to the courses where group work has a major role it is important to hear the voices of the "clients", that is industrial partners who will then hire the students for work. "Stakeholders' events" are arranged regularly to hear ideas and experiences on how the former students are doing and what aspects should be considered more in contemporary education. Similar idea is used by having contacts to the other universities, where automation is taught, in domestic level as well as abroad. Also, good contacts are formed to schools. That is a look into the future and is discussed in the next section.

\section{Luma Activity}

The future is not with us, it is in the young people. Even in the university level, the connections to schools are considered important. In Finland that is now organized in the Luma activity (Luma Centre Finland). "Luma" is actually very close to STEM education (Science, Technology, Engineering, Mathematics), the idea being to organize special courses and laboratory exercises to high school students and even to younger children. The purpose is to wake their interest in natural sciences and engineering, and later perhaps making the decision to start to study these disciplines. In the Luma centre Finland there are 13 different Luma units attached with universities across Finland. They all have different ways to operate: some have special Luma classes, where teachers can bring their students to do laboratory exercises; some arrange special courses and lectures to the students; some arrange student demonstrations and competitions e.g. in robotics etc. For example, in Luma centre Aalto there is a class (LUMARTS) with laboratory exercises in fields of biochemistry, chemistry, electrical engineering, meachanical engineering, and automation. Last year there were more than 2000 student visits in the class. Moreover, special courses on different topics are arranged regularly to high school students. Examples of such courses are micro- and nanosystems, robotics, space systems and mathematics.

In the LUMARTS class one class of problems is done with the Arduino platform, to get the students used to simple electronics applications and basic programming. Special courses in programming are also arranged, not only to the students but also to their teachers. The Luma activity is now pretty active in Finland and high interest and expectations are shown towards it, also in the political level.

To combine the ideas of the project work course described in the previous section and the Luma activity the following example can be given. In Figure 2 a laboratory example vessel has been presented. The exercise was constructed by a group of students in automation. The idea is to demonstrate the basic ideas of feedback control by using a liquid level control in a vessel as an example.

In the example the students can try tuning the liquid level manually, and they find it much more difficult than by an automatic PID-controller. It is clear that control mathematics (like the PID algorithm) cannot be taught at this level. However, the idea is again to wake an interest. Also, here the process represents something that also occurs in real process control and is then related to real work. (It is not an inverse double pendulum, which makes a nice demo, but is hardly related to most practical ap- 


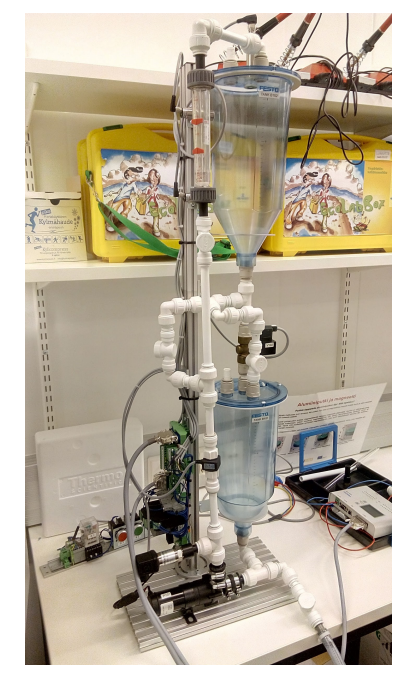

Figure 2. A simple process control system.

plications). Another example process constructed by the same project group is shown in Figure 3. It is a kind of a conveyor system, where a wooden ball is moved from one position to another by using a lift mechanism. The operation is controlled by a programmable logic controller, and one of the key targets in the exercise is to teach this kind of programming basics (ladder diagrams) to the students.

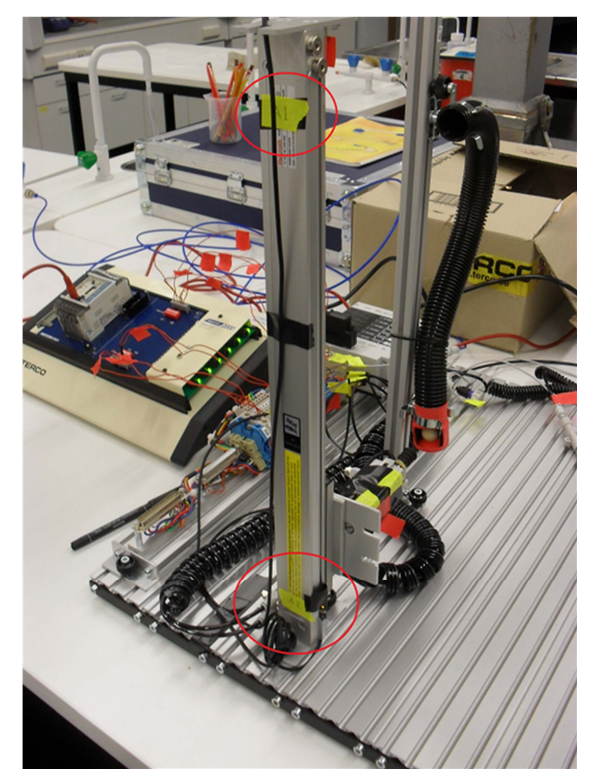

Figure 3. Autobygg system.

\section{Conclusions}

In the paper some modern concepts and ideas of control engineering education have been motivated and presented. The "new" methods are actually not very new and not very radical either. However, they are realistic and believed to meet the challenges that society sets to education in this field. It is also believed that the students in general like the more practical training they can get through the new kinds of courses. There is not yet enough student feedback to confirm or reject this hypothesis. Near future gives light to that issue also.

\section{References}

D. Ausubel. Educational psychology: A cognitive view. New York: Holt, Rinehart and Winston, 1968.

D. Boud and G. I. Feletti. The Challenge of Problem-based Learning. Psychology Press, 1977.

N. A. Kheir, K. J. Åström, D. Auslander, K. C. Cheok, G. F. Franklin, M. Masten, and M. Rabins. Control systems engineering education. Automatica, 32(2):147-166, 1996.

E. Mazur. Peer Instruction: A User's Manual Series in Educational Innovation. Prentice Hall, Upper Saddle River, NJ, 1997.

R. M. Murray. Future directions in control, dynamics and systems: Overview, grand challenges, and new courses. European Journal of Control, 9(2-3):144-158, 2003.

M. Pohjola, L. Eriksson, V. Hölttä, and T. Oksanen. Platform for monitoring and controlling educational laboratory exercises over internet. In Proceedings of the 16th IFAC World Congress, Prague, Czech Republic, 2005.

A. Rasila, M. Harjula, and K. Zenger. Automatic assessment of mathematics exercises: Experiences and future prospects. In Reflektori 2007 Symposium on Engineering Education, Espoo, Finland, pages 70-80, 2007.

V. Riihimäki, T. Ylöstalo, K. Zenger, and V. Maasalo. A new self-study course on the web: Basic mathematics in control. In Proceedings of the IFAC Symposium ACE 2003 (J. Lindfors, Ed.), Oulu, Finland, 2003, pages 149-153, 2003.

K. Zenger. Control engineering, system theory and mathematics: the teacher's challenge. Journal of Engineering Education, 32(6):687-694, 2007. 